\title{
COMUNICAÇÃO NA EDUCAÇÃO FORMAL: PROCESSO DE MUDANÇA
}

Na educação formal, aquela que se dá no âmbito da escola, constata-se a hegemonia do discurso verbal. Trata-se de uma educação "verbalizada", centrada na palavra e no discurso.

A magia da palavra acompanha o ser humano desde sempre. Sua condição de tornar presente o que está distante no tempo ou no espaço, de fazer viver de outro modo ou reviver o que já não está - sejam pessoas, situações -, sua condição de materializar sentimentos mais nobres ou menos nobres justificam esse fascínio.

No caso brasileiro, se por mais não fosse, pesa nossa própria tradição, que leva a população a apreciar os discursos com palavras "bonitas", muitas vezes carentes de significados para os que ouvem (e, muitas vezes, também para os que falam). É a nossa tradição bachaleresca que domina a cena.

O teatro, e depois a televisão, apresentaram-nos uma leitura desse traço cultural, por exemplo, no bem construído personagem Odorico Paraguaçu, de Dias Gomes. Na História, um dos exemplos mais completos parecem ter sido os famosos comícios do falecido Presidente Jânio Quadros, sobretudo quando de sua campanha para a Presidência do Brasil, em 1960.

Essa hegemonia do discurso verbal foi (e no geral ainda é) tão presente em nossas escolas, que, diante dele, quaisquer outros instrumentos adquiriram a condição de inferioridade, cujo uso indicava (indica) falta de competência e desmazelo, desinteresse ou preguiça do professor.

As águas pareciam ser absolutamente tranquiilas, pois ao lado do discurso verbal, o discurso não-verbal que circulava, até algumas décadas atrás, era o das histórias em quadrinhos, também impresso. O cinema, de

\section{A AUTORA}

Maria Aparecida Baccega

Professora Doutora do Departamento de Comunicações e Artes da ECA-USP. Especialista em Linguagem Verbal nos Meios de Comunicação. Autora de Concordância Verbal; Artigo \& Crase e Palavra e Discurso: história e literatura. 
tão grandes contribuições, passava ao largo da escola, apesar dos programas de cinema educativo de que nossa revista já tratou.

A chegada da televisão e sua rápida divulgação na nossa sociedade trazem modificações substanciais. Na atualidade, é a informática que se configura como instrumento indispensável. Ocorre que, no mais das vezes, essas conquistas tecnológicas continuam fora da escola. Aí reside o grande perigo. Ao invés de estarmos lutando para que a comunicação que nos chega através dos meios seja efetivamente praticada como um direito social, estamos ainda brigando contra essa modalidade de comunicação, como se a luta contra moinhos de vento pudesse resultar em alguma vitória consistente ou como se fosse dado a alguém ou a alguma instituição (no caso a escola) o direito de impedir os avanços tecnológicos e as mudanças dele decorrentes.

$\mathrm{O}$ direito à comunicação, aí incluídos os meios de comunicação, com tecnologia cada vez mais sofisticada, é hoje um dos direitos humanos fundamentais. Daí deriva uma política de comunicação que deveria possibilitar o acesso dos vários segmentos sociais à comunicação, e, desse âmbito, emergir a política de comunicação dirigida para a educação formal. $O$ Projeto TV Escola, que já foi objeto de nossa revista, é um exemplo dessa política.

O exercício do direito à comunicação está inserido no conjunto dos demais direitos - os chamados direitos sociais. Refletindo sobre eles, conhecendo um pouco de seus caminhos e descaminhos, podemos melhor avaliar as barreiras para a consecução de nossos objetivos. Tratando das questões contemporâneas com criticidade, elaboraremos procedimentos mais adequados para a política de comunicação dirigida à escola.

\section{ARTIGOS NACIONAIS}

Políticas sociais e direitos sociais no Brasil, de Evaldo Amaro Vieira, faz uma apresentação crítica da contemporaneidade, relacionando-a com as constituições brasileiras (e suas modificações), apontando os direitos sociais nelas presentes ou ausentes. Para tanto, chama logo de início a atenção: "Atualmente, não basta criticar a política social. É fundamental realizar a crítica da sua crítica, que quase sempre despreza a realidade e até a legitima pelo avesso. Quer dizer: ao desconhecer a realidade, confirma-a".

Neoliberalismo, desemprego, modernização, estado do bem-estar social são temas fundamentais, discutidos pelo autor, que os contextualiza na realidade do Brasil, "candidato a campeão mundial de desigualdade econômica”, no dizer de Hobsbawn.

Segundo a autor, "internacionalizam-se a criação e a difusão das indústrias de comunicação, tornando a 'globalização econômica' uma crescente 'americanização' da cultura de massa”. 
São esses, embora não se esgotem neste artigo, alguns dos temas a partir dos quais temos que pensar as questões referentes a políticas de comunicação.

E, no âmbito das políticas de comunicação voltadas para a educação formal, destaca-se a questão sempre presente da formação de professores. O artigo Formação de professores em tempos de informática, de Célia Pezzolo de Carvalho e Marisa Ramos Barbieri, aborda a questão, inserindo-a no lugar que é próprio de sua natureza: a formação de professores relaciona-se ao processo de educar, e educar é uma relação eminentemente humana. Condição tão simples e, atualmente, tão esquecida: parece que a formação de professores, hoje, relaciona-se tão somente com a técnica, a qual preencheria até o espaço das relações humanas.

Segundo as autoras, "cabe ao professor permanecer como agente de formação, indispensável na experiência educativa do aluno e não apenas como o transmissor de informações e habilidades necessárias", pois "um centro tecnológico na escola interessa não pela tecnologia mas pelo que se pode criar com ela".

Márcio Tadeu Magalhães, em Projeto Um salto para o futuro, nos relata os resultados de sua pesquisa sobre a implantação, em Mato Grosso, de um dos projetos governamentais para a formação e capacitação de professores: Um salto para o futuro.

$\mathrm{O}$ autor expõe as dificuldades dos professores interessados em seguir o Projeto, mostrando também se houve mudança na prática do professor em sala de aula, com seus alunos, e se foram ou não alterados os índices de evasão e repetência escolar em decorrência do Projeto. Por fim, aponta algumas alternativas, para discussão.

Salas pequenas e quentes funcionando como telepostos; espaços físicos de salas de aula que, na seqüência, abrigavam os alunos regulares, o que significava que, quando a transmissão se atrasava, era impossível segui-la, pois os alunos entravam para sua jornada; dificuldade com a sintonia do canal de transmissão; apadrinhamentos político-partidários, em detrimento da competência; material que não chega ao teleposto a tempo de ser usado pelo cursista são algumas das muitas dificuldades apontadas neste artigo.

Como se vê, são dificuldades que estão presentes em todo o país. Ao lado delas, a mais comum, que se relaciona diretamente às questões macropolíticas e econômicas, às políticas sociais e direitos sociais no Brasil pois dizem respeito à distribuição de renda e condições mínimas de dignidade para toda a população a que se refere à segurança da guarda dos equipamentos.

Apesar de todos esses empecilhos, as linguagens audiovisuais têm que estar presentes na escola. Afinal, a formação do cidadão exige a compreensão e a utilização dessas linguagens. É o que vai nos mostrar Marília Franco, no seu artigo Linguagens audiovisuais e cidadania. 
Tem-se claro que a linguagem audiovisual, sobretudo através da televisão, "vem formando a visão de mundo das novas gerações". É indispensável, portanto, segundo a autora, que o professor possa formar sua cidadania audiovisual docente. Para formá-la, o professor precisa "discutir os medos e preconceitos, reconhecer suas competências enquanto espectador/telespectador e pôr em foco essa pessoa social que gosta de TV e de cinema e o profissional-professor que pode levar essa competência para a sala de aula como apoio à atividade didática". E, nessa descoberta do prazer audiovisual, "a escola precisa encontrar a forma de resgatar a alegria do contato humano entre professores e alunos". Enfim, como dizem Célia P. de Carvalho e Marisa R. Barbieri, "educar é uma relação eminentemente humana". E as linguagens audiovisuais muito podem colaborar para o êxito do processo educativo, como demonstra Marília Franco.

Daí a utilização de Filmes nas aulas de História. Esse é o título que Antônio Reis Júnior dá a seu artigo. Nele, o autor vai tratar das aproximações e distanciamentos entre o gênero documentário e o gênero ficcional, mostrando como ambos são adequados para as aulas de História.

Apontando alguns aspectos do como trabalhar os filmes, o artigo chama a atenção para o fato de que, ainda que o filme apresente o tema em estudo apenas como pano de fundo, ele será benéfico: "sua utilidade residirá no fato de ele ser dinamizador de uma discussão. Ou seja, o filme dará o pontapé inicial do debate deste mesmo tema ou do período tratado na obra".

As linguagens, todas e em todas as modalidades, constituem o suporte dessa nova escola, que não mais poderá ignorá-las.

\section{ARTIGO INTERNACIONAL}

Se consideramos que a comunicação veiculada pelos meios se constitui hoje em um dos direitos humanos fundamentais e se advogamos que essa comunicação tem que estar nas escolas, centro de produção crítica, nada mais oportuno que trazer o artigo Comunicação plural: alteridade e sociabilidade, de Jesús Martín-Barbero, um dos maiores teóricos latino-americanos. Nele o autor discute as questões da comunicação, sobretudo na América Latina, no quadro da realidade contemporânea.

Segundo o autor, "cenário, expressivo como nenhum outro, das contradições desta época, os meios nos expõem cotidianamente à diversidade dos gostos e das razões, à diferença, mas também à indiferença; à crescente integração do heterogêneo das raças, das etnias, dos povos e dos sexos no sistema de diferenças com o qual, segundo Baudrillard, o Ocidente conjura e neutraliza, funcionaliza os outros (....), negando-lhe(s) a capacidade de interpelar-nos e de questionar-nos". 
Tratando dessas questões no contexto da globalização/regionalização, este artigo relaciona-se diretamente com as questões colocadas por Evaldo Amaro Vieira em Políticas sociais e direitos sociais no Brasil. A leitura dos dois, com os acréscimos e exemplificações dos demais, nos permitirá, certamente, a ampliação de nossas reflexões sobre a política de comunicação dirigida para a educação formal.

\section{ENTREVISTA}

Todos concordam que se trata de um excelente ator. Mas nem todos conhecem o grande cidadão que ele é também. Estamos falando de José Wilker, o entrevistado deste número. Na entrevista realizada por Roseli Fígaro - Em cena: versatilidade e bom humor-, ele fala de seus primeiros trabalhos em Recife, no Movimento de Cultura Popular. Fala também de teatro, cinema e televisão, incluindo-se telenovela e o programa Sai de Baixo.

\section{CRÍTICA}

Catarina Sant'Anna, especialista na teledramaturgia de Jorge Andrade, escreve sobre A telenovela Os ossos do Barão. Nesta crítica, a autora mostra a importância do dramaturgo para o teatro brasileiro, relembrando que sua primeira telenovela Os ossos do Barão, apresentada pela TV Globo em 1973, é resultado da fusão de duas peças de grande sucesso A escada e Os ossos do Barão.

No texto, podemos acompanhar as eternas brigas do autor com a censura da época e seus famosos bilhetinhos dirigidos ao diretor da telenovela.

Essa mesma telenovela será apresentada brevemente pelo SBT, com grande elenco e adaptação de Walter George Durst.

João de Jesus Paes Loureiro é autor de vasta obra, começada pelos idos de 60, nas lutas a favor da democracia. É o que se encontra em seu primeiro livro Tarefa. De lá para cá, muita História e muitos poemas. É sobre sua última obra que vem nos falar Gutemberg Guerra em $O$ espelho quebrado.

Trata-se de Cultura amazônica. Uma poética do imaginário, um estudo sobre os mitos da Amazônia.

\section{DEPOIMENTO}

Paulo Caruso é um dos maiores chargistas brasileiros. Em De $O$ Pasquim à Avenida Brasil, ele vai contando seu próprio trajeto ao mesmo tempo que traça o panorama da charge no Brasil das últimas décadas. Vale a pena ler. 


\section{EXPERIÊNCIA}

Jaine Rita C. Lino traz para nós a experiência que vem desenvolvendo com alunos de quinta à oitava séries, em Matemática e Geometria, utilizando a informática. Trata-se do programa Cabri-géomètre, cujos excelentes resultados você poderá verificar nesse relato.

Os vídeos também são usados. Mas não só. Leia em Imaginário, ficção, cotidiano: termos da mesma equação?, de Alice Vieira, o quanto a Oficina de Contos Clássicos não só colabora com os alunos, tornando-os mais desinibidos e criativos, como chega a possibilitar a feitura de livro, de autoria coletiva.

\section{POESIA}

Escolhemos, para este número da revista, a poesia de Jorge Andrade, que abre a publicação de suas peças teatrais: Veio das sombras. Desse modo, certamente o dramaturgo ficará mais próximo de nós.

\section{SERVIÇOS}

O Núcleo de Estudos da Violência da Universidade de São Paulo é bastante conhecido em todo o país. E também no Exterior. Afinal é ele que tem dado voz aos miseráveis, que tem batalhado por justiça e por condições dignas de vida. Pela cidadania, enfim.

Em A experiência do Núcleo de Estudos da Violência da USP, Paulo de Mesquita Neto nos fala de seus objetivos e de suas ações. Conheça, divulgue. Entre em contato. Participe.

\section{BOLETIM BIBLIOGRÁFICO}

Maria Ignês Carlos Magno centra suas sugestões, na seção Videografia, num dos temas mais discutidos hoje: a questão do espaço geográfico e humano. Experimente. Use os vídeos indicados. Acrescente outros, de acordo com a realidade de sua sala de aula. E, depois, escreva para nós, contando como foi. Também estão aí a Bibliografia sobre a telenovela brasileira, de Anamaria Fadul, e a Bibliografia na área de Comunicação e Educação, de Ismar de Oliveira Soares. Ambas têm sido bastante elogiadas pelos serviços que prestam. Escreva-nos você também. Participe com suas críticas e sugestões. Aguardamos. 